\title{
Estudo sobre os Fatores Contábeis que Influenciam o Índice FIRJAN de Desenvolvimento Municipal (IFDM) nas Capitais Brasileiras
}

\begin{abstract}
Resumo
O impacto dos gastos públicos sobre o desenvolvimento de um município pode ser considerado uma preocupação constante por parte dos governantes. Nesse cenário, como o cidadão é chamado a contribuir compulsoriamente, por meio de tributos, para a manutenção da estrutura da máquina administrativa municipal, este tem especial interesse na maximização do desenvolvimento humano da coletividade, sendo tal desenvolvimento passível de ser medido pelo Índice FIRJAN de Desenvolvimento Municipal (IFDM). O objetivo deste estudo consistiu em identificar as variáveis contábeis condicionantes do IFDM das capitais brasileiras, de modo a permitir avaliar a relevância da informação contábil no índice em questão. Para tal, foram abordadas questões referentes à accountability e transparência na gestão pública, bem como ao papel da evidenciação contábil na redução da assimetria informacional existente na relação entre os cidadãos e os governantes eleitos. Quanto aos procedimentos metodológicos, estimou-se um modelo de dados em painel a partir do cruzamento dos dados do IFDM das capitais brasileiras, considerado uma importante ferramenta de gestão pública e accountability democrática, referente aos exercícios de 2005 a 2010, com os dados de dezessete variáveis contábeis. Os resultados mostraram que as variáveis Juros e Encargos da Dívida, Despesa de Capital, Investimentos, gastos com Cultura e Assistência Social e Transferências Correntes apresentaram uma associação estatisticamente significativa com o IFDM total dos entes públicos selecionados, permitindo constatar que informações contábeis possuem relevância na determinação do IFDM das capitais analisadas. Esta situação corrobora a afirmativa de cunho teórico, segundo a qual os gastos governamentais registrados pela contabilidade afetam $o$ desenvolvimento de um município. Dessa forma, um bom gerenciamento das contas públicas poderia culminar em um aumento no nível de desenvolvimento humano dos municípios estudados ao longo dos anos.
\end{abstract}

Palavras-chave: Entidades Públicas. Accountability. IFDM.

\author{
Bruna Camargos Avelino \\ Mestre em Ciências Contábeis \\ (UFMG) e Doutoranda em \\ Controladoria e Contabilidade \\ (USP), Professora da Universidade \\ Federal de Minas Gerais (UFMG). \\ Contato: Av. Antonio Carlos, 6627, \\ Pampulha, Belo Horizonte, MG, \\ Brasil, CEP: 31270-901. \\ E-mail: bcavelino@gmail.com

\section{Valéria Gama \\ Fully Bressan \\ Pós-doutora em Economia Aplicada (UFV), Professora da Universidade Federal de Minas Gerais (UFMG). Contato: Av. Antonio Carlos, 6627, Pampulha, Belo Horizonte, MG, Brasil, CEP: 31270-901. \\ E-mail: vfully@face.ufmg.br}

\section{Jacqueline Veneroso}

Alves da Cunha

Doutora em Controladoria e Contabilidade (USP), Professora da Universidade Federal de Minas Gerais (UFMG). Contato: Av. Antonio Carlos, 6627, Pampulha, Belo Horizonte, MG, Brasil, CEP: 31270-901.

E-mail: jvac@face.ufmg.br 


\section{Introdução}

A execução pelo estado e municípios das atividades para as quais foram criados exige a disponibilidade de recursos financeiros. Nesse ponto, o cidadão é chamado a contribuir compulsoriamente, por meio de tributos, para a manutenção da estrutura da máquina administrativa estadual e municipal, bem como para a realização dos investimentos nas áreas de sua competência que considerar prioritárias, tais como educação, saúde, saneamento básico, transporte, infraestrutura, segurança pública, tecnologia e outras (Cruz, 2010). Essa arrecadação de tributos visa, em última instância, suportar gastos para a maximização do bem-estar da população. Em tese, quanto maior o gasto, maior o nível desse bem-estar (Scarpin, 2006).

Conforme esclarece Santos Filho (2010), tradicionalmente, sempre se buscou medir o crescimento e o desenvolvimento de uma sociedade a partir de fatores quantitativos econômicos, tais como PIB, PIB per capita, Renda, Renda per capita e investimentos. Esses indicadores, embora pudessem ser, de certa forma, eficientes como proxy do crescimento econômico, nem sempre refletiam o nível de desenvolvimento da sociedade, que normalmente tem reflexo no bem-estar social e na qualidade de vida (Santos Filho, 2010). Nesse cenário, surgiram indicadores mais voltados ao campo social, com destaque para o Índice de Desenvolvimento Humano (IDH).

Seguindo a mesma linha, Scarpin (2006) enfatiza que o progresso de um país ou município não pode ser mensurado apenas pelo dinheiro que possuem (ou carecem) seus cidadãos, mas, também, devem ser considerados aspectos relativos à saúde, qualidade dos serviços médicos e educação, de modo que essas medidas devem ser avaliadas não só pela disponibilidade, mas também pela qualidade. Santana Júnior (2008) acrescenta que, a partir do momento em que os cidadãos são compungidos a pagar tributos, também passam a cobrar das entidades públicas, por meio dos seus governantes e gestores, o cumprimento do contrato social. Com isso, os cidadãos têm por objetivo garantir que os recursos provenientes dos seus tributos estejam sendo empregados de maneira eficiente.

De modo análogo ao que acontece em uma organização privada com fins lucrativos, na esfera pública municipal, apesar de não haver um proprietário formal do município, existem diversos conflitos de agência. Podem-se considerar como proprietários do município os seus habitantes, que, por meio de eleições livres, escolhem seu prefeito, que será o administrador do município em um dado período (Scarpin, 2006). Porém, nem sempre o interesse do prefeito é convergente com os interesses da população em geral, fato que caracteriza um conflito de agência.

Segundo Slomski et al. (2008), ao se admitir a existência de assimetria informacional entre agente e principal, surge a necessidade de se avaliar se o agente (gestor público) sempre tomará as decisões que maximizem os interesses do principal (cidadãos). De acordo com Scarpin (2006), um dos maiores interesses dos cidadãos consiste na maximização do desenvolvimento humano da coletividade, sendo este desenvolvimento passível de ser medido pelo Índice de Desenvolvimento Humano Municipal (IDH-M) e, de forma similar, pelo Índice FIRJAN de Desenvolvimento Municipal (IFDM).

Estudos que analisam o IDH e estabelecem relações entre este e aspectos contábeis/financeiros são mais recorrentes na literatura do que aqueles que analisam o IFDM, destacando-se, dentre as pesquisas realizadas, os estudos de Anand e Sen (2000), Scarpin (2006) e Ray (2012). Anand e Sen (2000) analisaram o componente "Renda" do Índice de Desenvolvimento Humano, demonstrando as ambiguidades e inconsistências pontuais na utilização da variável em questão no modelo proposto pelo IDH. Os autores propuseram algumas correções na metodologia, em decorrência das divergências cruciais, mesmo em comparações entre países, entre rankings de PIB per capita. Dentre tais modificações, destacaram a necessidade da utilização precisa e consistente de variáveis relacionadas à renda, bem como a realização de correções com vistas a considerar os diferentes cenários de distribuição de renda. 
Scarpin (2006) apontou uma modelagem matemática para determinar o valor futuro do IDH-M para os municípios do Estado do Paraná, com base em dados contábeis atuais e outras variáveis. O autor analisou, também, a correlação entre os indicadores que fazem parte do IDH-M, verificou a relevância das informações contábeis na determinação do índice, identificou as variáveis que possuem relação com o IDH-M e mediu a defasagem temporal entre estas variáveis e o índice analisado.

Ray (2012), com ênfase na contabilidade para o desenvolvimento sustentável, propôs uma redefinição do IDH, incluindo no índice tradicional informações relacionadas ao meio ambiente, com o intuito de representar a sustentabilidade de forma mais adequada. O novo índice desenvolvido pelo autor, denominado Environmentally Stressed Human Development Index (ESHDI), indica o nível de estresse imputado por um país ao meio ambiente no processo de desenvolvimento econômico. Cruz (2010), por sua vez, utilizou o IFDM e o IDH-M como variáveis explicativas para testar a hipótese de que o nível de transparência da gestão pública dos 100 maiores municípios brasileiros, em termos de população, tem relação positiva com o desempenho alcançado pelo município nos índices mencionados.

Para que os interesses dos habitantes do município sejam alcançados, é dever do administrador eleito pela população gerir as finanças públicas de forma que o conjunto dos gastos possa fazer com que haja uma maximização do desenvolvimento (Scarpin, 2006). Nesse contexto, analisando-se o perfil do IFDM e a possível contribuição da contabilidade pública no sentido de registrar adequadamente o nível dos gastos públicos, formulou-se a seguinte questão de pesquisa: quais são os fatores contábeis condicionantes do IFDM? Para responder à questão de pesquisa, o estudo tem como objetivo geral identificar as variáveis contábeis condicionantes do IFDM das capitais brasileiras, de modo a permitir inferências sobre a relevância da informação contábil no índice em questão.

Como contribuição, o estudo visa estimular a elaboração de novos conhecimentos relativos ao impacto dos gastos públicos na formação do IFDM, uma vez que o IDH tem sido contemplado em um maior número de estudos, carecendo-se de mais pesquisas que analisem o IFDM. Além disso, espera-se poder contribuir para o direcionamento das políticas públicas no sentido de uma alocação mais eficiente de recursos.

\section{Plataforma Teórica}

\subsection{Accountability em Entidades Públicas}

No cenário contábil, a finalidade principal da divulgação de informações consubstancia-se em apoiar os usuários internos e externos da contabilidade na tomada de decisões. Desse modo, as demonstrações contábeis fornecem informações concernentes à posição patrimonial, financeira e econômica das empresas (Colauto et al., 2009). O objetivo da Contabilidade Governamental não foge à regra, já que deve controlar o patrimônio público e prestar contas à sociedade. Portanto, para a Contabilidade atingir essa meta, faz-se necessária a utilização de um sistema de informação contábil que permita o devido suporte no processo de tomada de decisões e a transparência dos gastos públicos (Athayde, 2002).

Assim como ocorre em empresas privadas, há uma grande diversidade e amplitude de interesses dos usuários diante das informações da contabilidade pública, como detalhado no Figura 1. 


\begin{tabular}{|c|c|}
\hline $\begin{array}{l}\text { Tipologia de usuários da } \\
\text { Contabilidade }\end{array}$ & Interesses dos usuários \\
\hline $\begin{array}{l}\text { Cidadãos, Contribuintes ou } \\
\text { Eleitores }\end{array}$ & $\begin{array}{l}\text { Exercer a participação política e o controle social, auxiliando a escolha e a } \\
\text { atuação de governantes que atendam aos seus anseios. }\end{array}$ \\
\hline Fornecedores & $\begin{array}{l}\text { Decidir as vendas ao Estado, por meio do conhecimento da demanda e da } \\
\text { capacidade de pagamento. Acompanhamento de licitações e de pagamentos } \\
\text { pelos órgãos públicos. }\end{array}$ \\
\hline Sindicatos & $\begin{array}{l}\text { Negociar remunerações, condições de trabalho e benefícios de servidores } \\
\text { públicos, de aposentados e pensionistas. }\end{array}$ \\
\hline Empresários & $\begin{array}{l}\text { Decidir a continuidade dos negócios, considerando alterações da carga tributária } \\
\text { e do incentivo à atividade econômica pelo estado, bem como oportunidades } \\
\text { de captação de empregados e dirigentes para os seus quadros de recursos } \\
\text { humanos. }\end{array}$ \\
\hline $\begin{array}{l}\text { Investidores (pessoas ou } \\
\text { instituições) }\end{array}$ & $\begin{array}{l}\text { Analisar o risco quanto à compra de títulos da dívida pública, entre outras } \\
\text { alternativas de investimentos afetadas pelo estado. }\end{array}$ \\
\hline ONGs e Associações & $\begin{array}{l}\text { Acompanhar e fiscalizar a ação governamental, de acordo com suas finalidades e } \\
\text { identificar áreas ou núcleos de cooperação ou suporte para as suas atividades. }\end{array}$ \\
\hline Partidos Políticos & $\begin{array}{l}\text { Embasar suas críticas e propostas governamentais (planos de governo), inclusive } \\
\text { através da alocação dos recursos públicos em ensino, pesquisa e extensão. }\end{array}$ \\
\hline Pesquisadores e Estudantes & $\begin{array}{l}\text { Desenvolver estudos acadêmico-científicos sobre o estado, sua gestão e as } \\
\text { finanças públicas. Localizar oportunidades e ou concentração dos recursos } \\
\text { potenciais ou reais destacados para a entidade. }\end{array}$ \\
\hline Instituições de Crédito & Embasar suas decisões de concessão de crédito ao estado. \\
\hline $\begin{array}{l}\text { Governos em outras esferas ou } \\
\text { Poderes }\end{array}$ & $\begin{array}{l}\text { Fiscalizar o uso de recursos, decisão de auxílio técnico e financeiro, instituição ou } \\
\text { alteração das normas vigentes. }\end{array}$ \\
\hline Governos estrangeiros & $\begin{array}{l}\text { Decidir sobre cooperação e auxílio financeiro, na forma de empréstimos ou } \\
\text { doações (transferências). }\end{array}$ \\
\hline Mídia (rádio, TV e Jornais) & Divulgar notícias e matérias investigativas. \\
\hline
\end{tabular}

Figura 1. Usuários externos das contas públicas e síntese de seus interesses presumíveis.

Fonte: Adaptado de Platt Neto et al. (2005).

De acordo com Pablos, Figueroa e Camou (2007), a interpretação da realidade que resulta do processo de prestação de contas das entidades públicas pode seguir dois tipos de lógica: a lógica da boa prática ou a lógica do correto. A lógica da boa prática, segundo os autores, é a lógica da ação inteligente que produz bons resultados; é a lógica da eficácia, da eficiência e da efetividade. A lógica do correto, por outro lado, é a lógica da legislação, o cumprimento dos métodos, normas e regras aplicáveis. O desafio é fazer com que ambas as lógicas coincidam, ou seja, que o que está em conformidade com a regra seja, ao mesmo tempo, o que produz resultados e soluciona problemas. Pablos, Figueroa e Camou (2007) acrescentam, ainda, a necessidade de haver um equilíbrio e uma concordância entre o discurso e a ação dos governantes; entre o que se diz e o que se faz. Assim, a tarefa dos governos democráticos consubstancia-se no desenvolvimento de uma ordem política que equilibre os dois momentos e as duas maneiras de abordar a realidade e, para atingir este objetivo, é fundamental que se desenvolvam mecanismos e instituições adequadas de prestação de contas, bem como de deliberação e julgamento das ações e resultados do governo (Pablos, Figueroa e Camou, 2007).

Nesse contexto, a divulgação de informações apresenta-se como um processo de relevância substancial, haja vista que a evidenciação possui papel de destaque na redução da assimetria informacional existente na relação entre a sociedade e os governantes eleitos. Desse modo, os governos têm por obrigação prestar contas de seus atos perante a sociedade, de forma a manter sua legitimidade. Tais governantes, por sua vez, só podem ser chamados a prestar contas quando há uma base de publicidade e transparência para uma cidadania informada e vigilante. Essas características se concretizam quando existe uma estrutura institucional que não se limita à revisão de um só fiscalizador oficial, mas permite, adicionalmente, a colaboração efetiva de diversos auditores independentes. Assim, a função fiscalizadora é realizada for- 
malmente pelas legislaturas, mas, também, pela imprensa livre, organizações civis, acadêmicos, analistas políticos e a interação de atores distintos da esfera política governo (Pablos, Figueroa e Camou, 2007). Surge, então, o conceito de accountability, que, segundo alguns autores, se aproxima do conceito da obrigação de se prestar contas dos resultados obtidos em função das responsabilidades que decorrem de uma delegação de poder (autoridade), consequentemente, há a geração de uma responsabilidade, que é a de prestar contas de seu desempenho e seus resultados (Corbari, 2004).

Poder, responsabilidade e prestação de contas são, portanto, conceitos inter-relacionados. Sem a delegação de poder ou uma certa capacidade de fazer as coisas, a accountability não pode ser requerida, uma vez que esta se manifesta, se justifica e se cumpre por meio de uma prestação de contas adequada. Esta prestação de contas envolve, por sua vez, evidenciar o desempenho da entidade pública, descrevendo e explicando o que tem sido feito (Martinez-González; Martí, 2006).

Para Graciliano et al. (2010), a accountability pode ser definida como a responsabilização permanente dos gestores públicos em termos da avaliação da conformidade/legalidade, bem como da economia, da eficiência, da eficácia e da efetividade dos atos praticados em decorrência do uso do poder que lhes é outorgado pela sociedade. Nesse cenário, Nakagawa, Relvas e Dias Filho (2007) defendem que a noção de accountability no setor público pode ser dividida da seguinte maneira: (a) dando explicações a todos os cidadãos, sejam eles eleitores ou não; (b) provendo informações posteriores sobre fatos relevantes, quando se tornarem necessárias; (c) revendo e, se necessário, revisando sistemas ou práticas para atingir as expectativas dos cidadãos, sejam eles eleitores ou não; e (d) concedendo compensações ou impondo sanções.

Para a Federação das Indústrias do Estado do Rio de Janeiro (FIRJAN), uma das vantagens do Índice FIRJAN de Desenvolvimento Municipal (IFDM) é permitir a orientação de ações públicas e o acompanhamento de seus impactos sobre o desenvolvimento dos municípios, constituindo-se em uma importante ferramenta de gestão pública e de accountability democrática.

\subsection{Gastos Públicos e Desenvolvimento}

A contabilidade desempenha um papel fundamental como instrumento para melhorar a performance do setor público (Hood, 1991). De acordo com o National Council on Governmental Accounting - NCGA (1982), o objetivo geral da informação contábil e financeira em órgãos governamentais consiste em: (1) prestar de informações financeiras que sejam úteis para a tomada de decisões políticas, econômicas e sociais, demonstrando responsabilidade e boa gestão, e (2) fornecer informações que possam ser úteis para avaliar o desempenho e as ações da organização. Conforme ressalta Santos Filho (2010), a Contabilidade Aplicada ao Setor Público possibilita a evidenciação dos gastos públicos de diversas maneiras a partir de diversas classificações orçamentárias (institucional, funcional, estrutura programática, natureza da despesa). Porém, independente da forma de evidenciação, cabe a ela o registro adequado do nível desses dispêndios.

A partir dos dados contábeis consolidados, pode-se obter o volume de recursos públicos gastos em áreas específicas, tais como administração e planejamento, educação e cultura, habitação e urbanismo, saúde e saneamento, assistência e previdência, transportes, em qualquer nível de agregação. Pode-se, também, identificar contabilmente o quanto foi gasto com juros e encargos da dívida, pessoal e investimentos em um determinado município, estado, região ou país. A Contabilidade fornece, ainda, informações concernentes às receitas arrecadadas pelos entes públicos, sejam estas classificadas como receitas correntes, tributárias e/ou transferências correntes. Nesse contexto, a contabilidade pública procura atingir seus objetivos de registro, controle, transparência, prestação de contas e divulgação de informações.

March e Olsen (1995) salientam, no entanto, que as contas públicas não se limitam apenas às operações aritméticas das receitas e gastos realizados, mas se constituem, principalmente, em uma proposta de construção e explicação da realidade política. Trata-se, consequentemente, de um processo de construção da realidade na qual sua interpretação não é imposta verticalmente de cima, de forma que a proposta do gover- 
nante é revisada, observada e avaliada por outros atores independentes, que não necessariamente detenham os mesmos interesses ou os mesmos valores.

Os gastos públicos e, por consequência, a receita pública, não devem ser analisados, portanto, como números isolados e fora de um contexto político, tendo em vista que estes afetam o desenvolvimento de um município, seja na questão da redução de externalidades negativas, seja na questão dos bens públicos (Scarpin, 2006). De acordo com Kon (1997, p. 35), "as externalidades positivas representam as economias nos custos produtivos e os benefícios para os agentes que as usufruem, enquanto que as negativas ou deseconomias se associam a prejuízos, aumentos nos custos, desvantagens". Em outras palavras, as externalidades negativas ocorrem quando a ação de uma das partes impõe custos sobre a outra (Scarpin, 2006).

Scarpin (2006) ressalta que a expansão dos gastos públicos se relaciona com o seu papel de produção dos bens públicos e de controle de externalidades em uma economia de mercado. Nesse sentido, a intervenção governamental pelas despesas públicas é dada por duas vias. A primeira delas é o bem público propriamente dito, que não pode ser feito pelo mercado, como é o caso da segurança pública. Também existem os bens públicos para a produção de externalidades positivas, como é o caso de uma campanha de vacinação, visto que, quando se imuniza a população contra uma doença transmissível, há um grande benefício implícito, que é a segurança de que a população não sofrerá da doença (Scarpin, 2006).

Desse modo, um bom gerenciamento das contas públicas, incluindo nessa denominação as receitas e os gastos públicos registrados pela contabilidade, tende a fazer com que os municípios tenham seu nível de desenvolvimento humano aumentado ao longo dos anos. Conforme já mencionado, os gastos públicos e, por consequência, a receita pública, afetam o desenvolvimento de um município, sendo função da controladoria municipal a elaboração de sistemas de informação para acompanhamento da receita e dos gastos municipais. Tais suportes informacionais, de acordo com Scarpin (2006), são fundamentais para eliminar os conflitos de interesses entre a sociedade e os governantes eleitos, visto que o administrador público pode ter outros interesses que não a maximização do desenvolvimento, mas, sim, a espoliação do patrimônio público para fins próprios, direcionamento de gastos para aliados políticos, uma futura reeleição ou eleição para outros cargos públicos.

\section{3. Índice FIRJAN de Desenvolvimento Municipal (IFDM)}

O Índice FIRJAN de Desenvolvimento Municipal (IFDM) nasceu em resposta à necessidade de se monitorar anualmente o desenvolvimento socioeconômico de uma região, considerando as diferentes realidades de sua menor divisão federativa: o município (FIRJAN, 2010). O IFDM avalia, com igual ponderação, as três principais áreas de desenvolvimento humano: 'Emprego e Renda,' 'Educação' e 'Saúde'. A leitura dos resultados - seja por áreas de desenvolvimento, seja pela análise dos índices finais - varia de 0 a 1, de modo que quanto mais próximo de 1, maior será o nível de desenvolvimento da localidade (FIRJAN, 2010).

Com base nessa metodologia, o Sistema FIRJAN estipulou as seguintes classificações:

a) municípios com IFDM entre 0 e 0,4: baixo estágio de desenvolvimento;

b) municípios com IFDM entre 0,4 e 0,6: desenvolvimento regular;

c) municípios com IFDM entre 0,6 e 0,8: desenvolvimento moderado;

d) municípios com IFDM entre 0,8 e 1,0: alto estágio de desenvolvimento.

O índice tem periodicidade anual, porém, encontram-se disponíveis apenas cálculos para os anos de 2000, 2005, 2006, 2007, 2008, 2009 e 2010. Em relação à publicação do ranking referente ao ano de 2000, houve uma defasagem temporal de oito anos, uma vez que este foi publicado em 2008, mas com dados referentes a 2000. De forma similar, os rankings concernentes aos períodos de 2005, 2006, 2007 e 2008 apresentaram defasagem de três anos, haja vista que foram publicados, respectivamente, nos anos de 2008, 2009,2010 e 2011. Finalmente, quanto à publicação dos rankings referentes aos anos de 2009 e 2010, estes foram disponibilizados, respectivamente, nos anos de 2011 e 2012, apresentando defasagem de dois anos. 
Conforme salientado pela FIRJAN (2010), essas defasagens decorrem do fato de serem utilizadas apenas estatísticas oficiais para o cálculo do índice. Desse modo, em algumas situações, são necessários longos períodos para reunir concomitantemente dados dos Ministérios da Educação, da Saúde e do Trabalho. Na Figura 2, observa-se um quadro-resumo das variáveis que compõem o cálculo do Índice FIRJAN de Desenvolvimento Municipal.

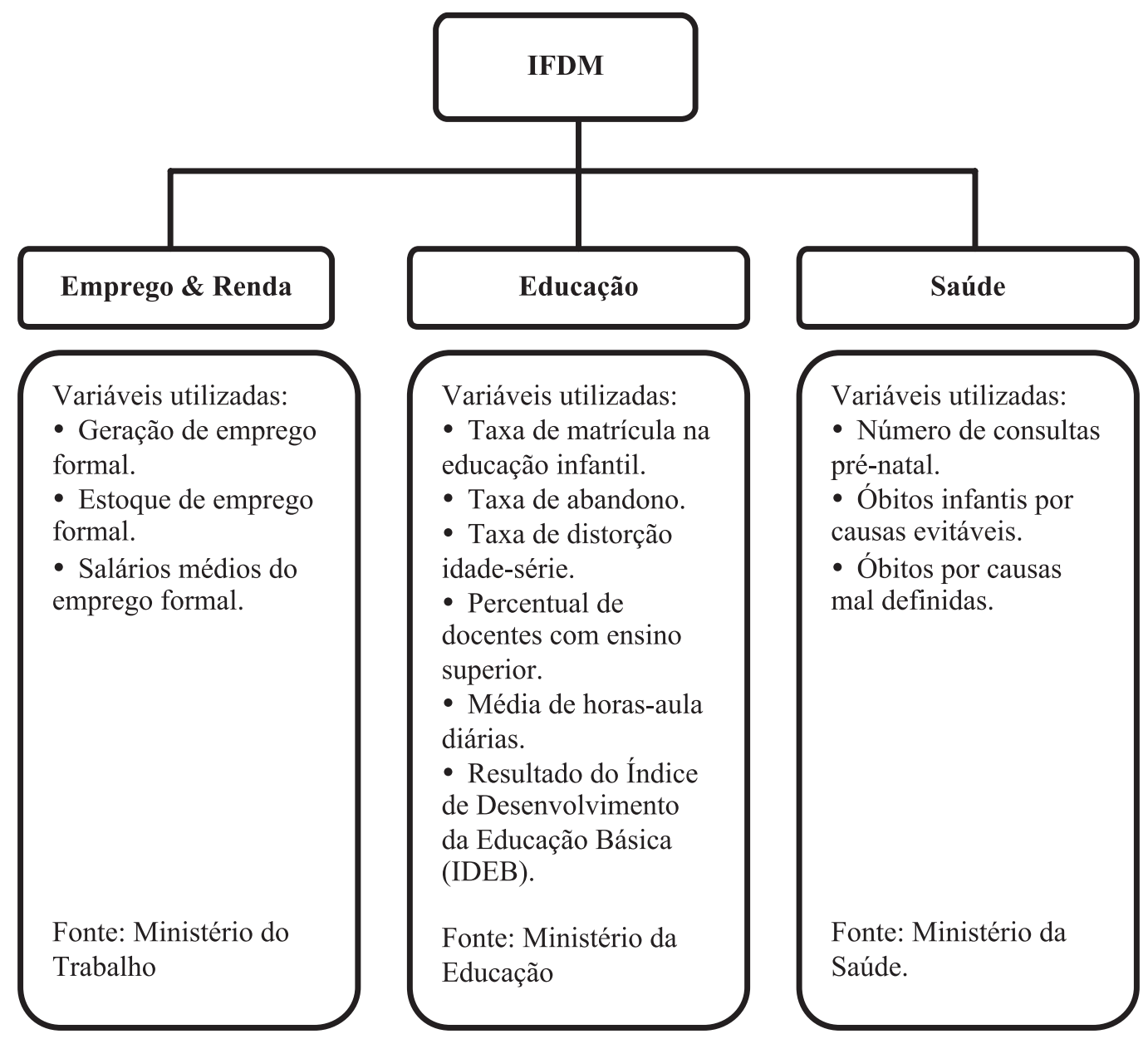

Figura 2. Quadro-resumo das variáveis que compõem o cálculo do IFDM.

Fonte: IFDM 2010. Disponível em: <www.firjan.org.br>. Acesso em: 23 set. 2011.

A primeira área abordada pelo IFDM é o emprego formal e a renda da população empregada. O IFDM-Emprego e Renda acompanha a movimentação e as características do mercado formal de trabalho, com base nos dados disponibilizados pelo Ministério do Trabalho (FIRJAN, 2010). A segunda área do IFDM, a Educação, constitui-se em um dos principais pilares para o desenvolvimento de um país. O IFDM-Educação foi idealizado para captar tanto a oferta como a qualidade da educação do ensino fundamental e pré-escola, oferecido nos municípios brasileiros, em escolas públicas e privadas, segundo as competências constitucionais de todo município. Vale ressaltar que se pode exigir que todo município apresente ao menos ensino fundamental de qualidade, haja vista que não é expressamente de competência destes manter o ensino médio (de competência estadual) e o ensino superior (FIRJAN, 2010).

A terceira e última área considerada no IFDM refere-se à Saúde. De acordo com a FIRJAN (2010), analisar a Saúde por meio das estatísticas disponíveis é um desafio, pela falta de consenso entre os pesquisadores sobre quais os melhores indicadores da situação do serviço público. Assim, o IFDM-Saúde procura focar na saúde básica e utilizar bancos de dados considerados pelos especialistas como relevantes e confiáveis, priorizando os dados dos Sistemas de Informação sobre Mortalidade (SIM) e os bancos de dados sobre Nascidos Vivos (Sinasc). 


\section{Metodologia}

\subsection{Unidades de Análise, Coleta de Dados e Caracterização das Variáveis}

O estudo, de caráter descritivo, utilizou análise documental e abordagem quantitativa. A pesquisa foi realizada pelo cruzamento dos dados do IFDM, referentes aos exercícios de 2005 a 2010, disponíveis no endereço eletrônico da Federação das Indústrias do Estado do Rio de Janeiro (FIRJAN), com os dados das variáveis contábeis das capitais brasileiras disponíveis no site do Tesouro Nacional, por meio do software Finanças do Brasil (FINBRA). O programa supracitado foi desenvolvido pela Secretaria Nacional do Tesouro (STN) com o intuito de divulgar dados de execução orçamentária dos municípios brasileiros, comportando uma base de dados contábeis referentes aos exercícios financeiros compreendidos entre 1989 e 2011. No presente estudo, foram utilizados dados de 2005 a 2010, uma vez que estes foram os anos base considerados para o cálculo do IFDM, não sendo disponibilizadas no site da FIRJAN as informações referentes aos exercícios de 2001 a 2004.

Com a finalidade de atingir o objetivo proposto, foi testada na pesquisa a seguinte hipótese:

\section{$\mathbf{H}_{1}$ : Os montantes dos saldos em contas registrados pela contabilidade pública são fatores explicativos} associados à determinação do IFDM do município na sua forma total.

Tal hipótese foi analisada no estudo de Scarpin (2006) em relação aos municípios do estado do Paraná, porém, o autor utilizou como variável dependente o Índice de Desenvolvimento Humano Municipal (IDH-M) nas dimensões Educação, Longevidade e Renda. No presente estudo, optou-se por utilizar o IFDM em detrimento do IDH-M por este ser anual, enquanto o IDH-M é decenal, já que é realizado com base nos dados do Censo Populacional que, atualmente, é realizado no Brasil a cada dez anos (FIRJAN, 2010). Assim, optou-se pela análise do IFDM por este apresentar dados mais atualizados e uma série temporal maior, tendo em vista que o último ranking do IDH-M para municípios brasileiros disponibilizado pelo software Atlas do Desenvolvimento Humano no Brasil foi realizado com informações referentes ao ano de 2000.

Pressupõe-se que a substituição do IDH-M pelo IFDM, em função deste último estar mais atualizado e apresentar uma série temporal maior, não prejudicará a análise dos resultados, tendo em vista as similaridades entre os dois índices e a alta correlação positiva entre estes, conforme Tabela 1.

Tabela 1

Coeficientes de correlação (Pearson)

\begin{tabular}{lccc}
\cline { 2 - 3 } & & IFDM 2000 & IDH-M 2000 \\
\cline { 2 - 4 } & IFDM 2000 & 1,000 & \\
\hline IDH-M 2000 & $\mathbf{0 , 7 9 3}$ & 1,000 \\
\hline
\end{tabular}

Fonte: Elaborada pelos autores a partir de dados extraídos do STATA ${ }^{\oplus}$.

De acordo com a hipótese elaborada, foram selecionadas, a principio, além da variável dependente IFDM total, dezessete variáveis contábeis independentes, já analisadas na pesquisa de Scarpin (2006). Estudos como os de Ferreira (1996), Devarajan, Swarrop e Zou (1996), Ferreira e Milliagros (1998), Rocha e Giuberti (2007), Ghosh e Gregoriou (2008), entre outros, exploraram os efeitos do capital público sobre o crescimento econômico e/ou a produtividade, porém, o estudo de Scarpin (2006) destacou-se por ter contribuído com a elaboração de novos conhecimentos relativos ao impacto dos gastos públicos, representados por uma série de variáveis contábeis, na formação do IDH-M, índice que vai além da mensuração do de- 
senvolvimento econômico. Por esse motivo, optou-se por utilizar a pesquisa de Scarpin (2006) como base para este estudo. Vale ressaltar que o autor supracitado analisou, também, variáveis não contábeis, no entanto, na presente pesquisa, estas não foram abordadas, por se pretender avaliar a contribuição da contabilidade, de forma isolada, como possível fator condicionante do IFDM. Em relação às variáveis contábeis, no estudo de Scarpin (2006) somente a Receita Tributária e a Despesa com Pessoal mostraram-se significativas como fatores explicativos do IDH-M total.

As definições das variáveis independentes foram retiradas do estudo de Scarpin (2006) e do glossário do software Situação Fiscal do seu Município, desenvolvido pela Secretaria Nacional do Tesouro (STN):

- Despesa com Pessoal: montante correspondente às despesas de toda natureza (inclusive encargos sociais) devidas a pessoal, exceto aquelas destinadas a indenizações trabalhistas, originárias de sentenças judiciais e referentes a exercícios anteriores.

- Juros e Encargos da Dívida: montante correspondente às despesas com o pagamento de juros, comissões e outros encargos relativos à dívida pública interna e externa, contratual e mobiliária.

- Despesa de Capital: tem por propósito formar e/ou adquirir um bem de capital de modo a contribuir para o incremento da capacidade produtiva.

- Investimentos: agrupa toda e qualquer despesa relacionada ao planejamento e execução de obras, aquisição de imóveis e instalações, equipamentos e material permanente, constituição ou aumento de capital de empresas que não sejam de caráter comercial ou financeiro.

- Administração e Planejamento: correspondente ao somatório das despesas com administração, ciência e tecnologia e encargos especiais (refinanciamento da dívida interna e externa, serviço da dívida interna e externa e transferências).

- Educação: correspondente às despesas com educação, evidenciadas na função de número 12 (educação).

- Cultura: representa o gasto com cultura, caracterizado na função de número 13 (cultura) do orçamento das despesas públicas.

- Urbanismo: apresenta o gasto do município com urbanismo, evidenciado na função 15 (urbanismo).

- Habitação: corresponde ao gasto do município com habitação, evidenciado na função 16 (habitação).

- Saúde: representa o gasto do município com saúde, caracterizado na função de número 10 (saúde).

- Saneamento: corresponde às despesas com saneamento, representadas pela função 17 (saneamento).

- Assistência Social: apresenta o gasto do município com assistência, evidenciado na função 08 (assistência social).

- Previdência: corresponde às despesas com previdência, caracterizadas na função de número 09 (previdência social) do orçamento das despesas públicas.

- Transporte: apresenta o gasto do município com transporte, evidenciado na função 26 do orçamento das despesas públicas.

- Receita Corrente: refere-se às receitas que aumentam somente o patrimônio não duradouro do Estado, isto é, que se esgotam dentro do período compreendido pela lei orçamentária anual. Compreende os seguintes grupos: tributária, de contribuição, patrimonial, agropecuária, industrial, de serviços, transferências correntes, outras receitas correntes.

- Receita Tributária: refere-se aos impostos, taxas e contribuições auferidos pelo município.

- Transferências Correntes: correspondem às transferências intergovernamentais do Estado e da União, referentes a impostos estaduais e federais, bem como ao fundo de participação dos municípios. 


\subsection{Modelo Analítico}

A técnica estatística utilizada para identificar as variáveis contábeis que possuem relação com o IFDM consistiu na regressão com dados em painel. Esse método permite que regressões sejam estimadas considerando-se várias entidades (cross-sectional) por um determinado período de tempo (séries temporais). Assim, os dados em painel têm uma dimensão espacial e outra temporal. Dentre as vantagens oferecidas por este tipo de análise, destacam-se a possibilidade do controle da heterogeneidade presente nos indivíduos, além de permitir o uso de mais observações, aumentando o número de graus de liberdade e diminuindo a multicolinearidade entre as variáveis explicativas (Hsiao, 1986).

No entanto, conforme salienta Baltagi (2005), quando se trabalha com dados em painel, tem-se as seguintes limitações: (1) problemas de coleta de dados; (2) distorções resultantes de erros de medidas; (3) problemas de seletividade, resultantes de dados faltantes que geram painéis não balanceados; e (4) dimensão de série temporal curta.

O modelo geral para análises econométricas, utilizando dados em painel pode ser representado de modo simplificado por:

$$
y_{i t}=\alpha+x_{i} \beta+v_{i}+\varepsilon_{i t}
$$

Em que:

- $\mathrm{i}=1, \ldots, \mathrm{N}$ (representa as unidades cross-section);

- $\mathrm{t}=1, \ldots, \mathrm{N}$ (indica a série temporal);

- $y_{i t}=$ indica a variável dependente;

- $\alpha=$ é o intercepto do modelo;

- $x_{i t}=$ indica as variáveis independentes do modelo (existem $\mathrm{k}$ regressores em $x_{i t}$ );

- $\beta=$ representa os coeficientes angulares estimados para cada variável independente; $\mathrm{e}$

- $v_{i}+\varepsilon_{i t}=$ são os erros do modelo. Segundo Baltagi (2005), $v_{i}$ é o componente que indica o efeito individual específico não observável, que difere entre as unidades e é invariante no tempo; enquanto $\varepsilon_{i t}$ consiste no componente que varia com as unidades e com o tempo, denominado erro "usual" da regressão. Ressalta-se que, neste estudo, como cada entidade "i" dispõe do mesmo número de dados temporais, tem-se um painel balanceado (ou equilibrado).

Podem-se elencar três tipos de modelos de dados em painel, a saber: o de coeficiente constante (ou pooled regression), o de efeitos fixos e o de efeitos aleatórios. O primeiro pressupõe que todos os coeficientes são constantes ao longo do tempo e entre indivíduos (aqui representados pelas capitais brasileiras). De acordo com Gujarati (2006, p. 517), esta é "a maneira mais simples e possivelmente ingênua" de estimação, uma vez que desconsidera as dimensões de tempo e espaço dos dados combinados e estima a habitual regressão de MQO.

O modelo de efeitos fixos é adequado a situações em que o intercepto específico ao indivíduo pode estar correlacionado com um ou mais regressores. Uma desvantagem do modelo de efeitos fixos é o fato de este consumir um grande número de graus de liberdade quando o número de unidades de corte transversal, $\mathrm{N}$, é muito grande, já que é necessário incluir um número significativo de variáveis dummy (Gujarati, 2006). Além disso, esse tipo de modelo pode apresentar multicolinearidade.

No modelo de efeitos aleatórios, pressupõe-se que o intercepto de uma unidade individual é uma extração aleatória de uma população muito maior com um valor médio constante. Uma vantagem do modelo de efeitos aleatórios em relação ao modelo de efeitos fixos é que este é econômico em graus de liberdade, já que não é necessário estimar $\mathrm{N}$ interceptos individuais, mas somente o valor médio do intercepto e sua variância (Gujarati, 2006).

Dadas essas possibilidades de estimação, o questionamento a ser feito é: qual modelo deve ser utilizado? A estimação do modelo com efeitos fixos leva em conta a "individualidade" de cada entidade, 
podendo ser considerado adequado para este estudo. Vale salientar que, neste caso, presume-se que os coeficientes angulares são constantes, mas o intercepto varia entre as entidades, embora possam ser encontradas outras possibilidades de premissas a respeito do intercepto, dos coeficientes angulares e do termo de erro em Gujarati (2006). Assim, para detectar a conveniência da utilização do modelo pooled ou do modelo de painel com efeitos fixos, empregou-se o teste de Chow. De acordo com Baltagi (2005), esse teste avalia se os efeitos individuais são estatisticamente iguais a zero, ou seja, não existem efeitos individuais específicos (hipótese pooled) versus a hipótese alternativa de que esses efeitos são estatisticamente diferentes de zero (hipótese de efeitos fixos).

A alternativa de estimação por dados em painel com efeitos aleatórios também é uma opção aceitável para a análise da presente pesquisa, haja vista que este método assume que os municípios incluídos na amostra foram retirados de um universo maior, que engloba todos os municípios brasileiros. Por esse motivo, realizou-se o teste de Breusch-Pagan para avaliar a conveniência da utilização do modelo pooled ou do modelo de painel com efeitos aleatórios. Tal teste avalia se a variância dos efeitos individuais não observáveis é estatisticamente igual a zero (hipótese pooled) versus a hipótese alternativa de que essa variância é estatisticamente diferente de zero (hipótese de efeitos aleatórios). Após, aplicou-se o teste de Hausman para selecionar qual dos modelos para dados em painel é o mais apropriado: o modelo de efeitos aleatórios $\left(\mathrm{H}_{0}\right)$ ou o modelo de efeitos fixos $\left(\mathrm{H}_{\mathrm{A}}\right)$.

Ressalta-se que o modelo de dados em painel pode gerar vários problemas de estimação e de inferência, a partir dos dados cross-section (heterocedasticidade) e séries temporais (autocorrelação). Desse modo, para testar a heterocedasticidade entre os painéis, aplicou-se o teste de Wald modificado. Esse teste faz parte do conjunto de testes disponibilizados no software STATA ${ }^{\oplus}$. Calcula-se a estatística de Wald modificada, considerando-se como hipótese nula a de que a variância do erro é homocedástica (Gomes, 2007). Para testar a presença de autocorrelação serial dos erros, aplicou-se o teste de Wooldridge de autocorrelação serial. O teste de Wooldridge tem como hipótese nula "presença de autocorrelação serial" de ordem superior, contra "ausência de autocorrelação".

\section{Análise dos Resultados}

Diante das três possibilidades de estimação com dados em painel, e considerando-se que os três modelos poderiam ser aplicáveis ao estudo, alguns passos foram seguidos para se decidir qual modelo deveria ser utilizado. A princípio, estimou-se o modelo pooled e o modelo com efeitos fixos. Para detectar a conveniência da utilização do modelo pooled ou do modelo de painel com efeitos fixos, empregou-se o teste de Chow. O valor-p encontrado no referido teste foi de 0,0000 , assim, considerando-se $\alpha=0,05$, rejeitou-se $\mathrm{H}_{0}(\mathrm{p}<\alpha)$, o que denota a conveniência da utilização do modelo de efeitos fixos.

Em seguida, estimou-se o modelo com efeitos aleatórios. Para detectar a conveniência da utilização do modelo pooled em detrimento do modelo de painel com efeitos aleatórios, realizou-se o teste de Breusch-Pagan. O valor-p encontrado no teste foi de 0,0000 , desse modo, considerando-se $\alpha=0,05$, rejeitou-se $\mathrm{H}_{0}(\mathrm{p}<\alpha)$, o que implica a conveniência da utilização do modelo de efeitos aleatórios.

Por fim, verificada a inadequabilidade da utilização do modelo pooled, tendo em vista a rejeição da hipótese nula nos testes de Chow e Breusch-Pagan, aplicou-se o teste de Hausman para selecionar qual dos modelos para dados em painel seria o mais apropriado: o modelo de efeitos aleatórios $\left(\mathrm{H}_{0}\right)$ ou o modelo de efeitos fixos $\left(\mathrm{H}_{\mathrm{A}}\right)$. O valor-p encontrado no teste foi de 0,1482 , assim, considerando-se $\alpha=0,05$, não se rejeitou $\mathrm{H}_{0}(\mathrm{p}>\alpha)$, o que implica a conveniência da utilização do modelo de efeitos aleatórios.

Definido o modelo de estimação com dados em painel mais adequado ao estudo (efeitos aleatórios), empregou-se o teste de Wooldridge de autocorrelação serial para testar a presença de autocorrelação serial dos erros. O valor-p encontrado foi de 0,0000 , indicando a existência de problemas de autocorrelação. No que tange à presença de heterocedasticidade, foi aplicado o teste de Wald modificado. O valor-p encontrado foi de 1,0000, indicando a não existência de problemas de heterocedasticidade. 
Desse modo, em função de o modelo estimado no presente estudo apresentar problemas de autocorrelação, o procedimento metodológico utilizado foi fundamentado na sugestão de Judge et al. (1985 apud Bressan, 2009), que aponta o uso do modelo de dados em painel linear usando Mínimos Quadrados Generalizados Factíveis (Feasible Generalized Least Squares) como a alternativa que permite a estimação de modelos em painel na presença de autocorrelação.

A estrutura básica do modelo de regressão em painel utilizada nesta pesquisa é então representada por:

$$
\begin{aligned}
& I F D M_{i t}=\alpha+\beta P E S S O A L_{i t}+\beta J U R O S+\beta D E S P C A P+\beta I N V+\beta A D M P L A N+ \\
& +\beta E D U C_{i t}+\beta C U L T_{i t}+\beta H A B I T+\beta U R B_{i t}+\beta S A U D+\beta S A N_{i t}+\beta A S S I S T+ \\
& +\beta P R E V_{i t}+\beta \text { TRANSP }_{i t}+\beta R E C O R+\beta R E C T R I B+\beta T R A N S F+v_{i}+\varepsilon_{i t}
\end{aligned}
$$

Em que:

$\mathrm{i}=1, \ldots, 26$ (representa as entidades públicas analisadas);

$\mathrm{t}=1, \ldots, 4$ (indica os períodos analisados: 2005 a 2010);

IFDM = Índice FIRJAN de Desenvolvimento Municipal total (constitui a variável dependente do modelo);

$\alpha=$ é o intercepto do modelo;

$\beta=$ representa os coeficientes angulares estimados para cada variável independente;

As variáveis descritas a seguir consistem nas variáveis independentes do modelo:

PESSOAL = Despesa com Pessoal;

JUROS = Juros e encargos da dívida;

DESPCAP = Despesa de Capital;

INV = Investimentos;

ADMPLAN = gastos com Administração e Planejamento;

EDUC = gastos com Educação;

CULT = gastos com Cultura;

HABIT = gastos com Habitação;

$\mathrm{URB}=$ gastos com Urbanismo;

SAUD = gastos com Saúde;

SAN = gastos com Saneamento;

ASSIST = gastos com Assistência;

PREV = gastos com Previdência;

TRANSP = gastos com Transporte;

RECOR = Receitas Correntes;

RECTRIB = Receita Tributária;

TRANSF $=$ Transferências Correntes, e;

$v_{i}+\varepsilon_{i t}$ representando os erros do modelo.

Os resultados obtidos no modelo de dados em painel estimado, usando Mínimos Quadrados Generalizados Factíveis (FGLS), estão descritos na Tabela 2. 
Tabela 2

Variáveis contábeis condicionantes do IFDM das 26 capitais analisadas no estudo

\begin{tabular}{|c|c|c|c|}
\hline IFDM & Coeficientes & Erro-padrão & Valor-p \\
\hline PESSOAL & $1,64 \mathrm{e}-11$ & $2,00 \mathrm{e}-11$ & 0,413 \\
\hline JUROS & $-4,66 e-10$ & $1,24 \mathrm{e}-10$ & 0,000 \\
\hline DESPCAP & $-1,19 e-10$ & $3,86 e-11$ & 0,002 \\
\hline INV & $1,37 e-10$ & $5,60 e-11$ & 0,015 \\
\hline ADM & $1,95 \mathrm{e}-11$ & $5,16 e-11$ & 0,706 \\
\hline EDUC & $5,67 e-11$ & $7,44 \mathrm{e}-11$ & 0,446 \\
\hline CULT & $5,76 \mathrm{e}-10$ & $2,19 \mathrm{e}-10$ & 0,009 \\
\hline HABIT & 1,11e-10 & 1,13e-10 & 0,326 \\
\hline URB & $-8,43 e-13$ & $3,55 \mathrm{e}-11$ & 0,981 \\
\hline SAUD & $3,83 e-11$ & $4,06 e-11$ & 0,345 \\
\hline SAN & $-3,75 e-11$ & $6,10 e-11$ & 0,539 \\
\hline ASSIST & $-5,23 e-10$ & $2,08 \mathrm{e}-10$ & 0,012 \\
\hline PREV & $-1,74 \mathrm{e}-11$ & $2,44 \mathrm{e}-11$ & 0,475 \\
\hline TRANSP & $3,99 e-11$ & $7,64 \mathrm{e}-11$ & 0,601 \\
\hline RECOR & $5,05 e-11$ & $2,89 \mathrm{e}-11$ & 0,080 \\
\hline RECTRIB & 4,61e-11 & $4,36 \mathrm{e}-11$ & 0,291 \\
\hline TRANSF & $-1,17 e-10$ & $4,01 \mathrm{e}-11$ & 0,004 \\
\hline Constante & 0,7701048 & 0,0080919 & 0,000 \\
\hline $\mathrm{N}^{\circ}$ Obs: 156 & & & $\mathrm{~N}^{\circ}$ de grupos: 26 \\
\hline
\end{tabular}

Fonte: Elaborado pelos autores a partir de dados extraídos do STATA ${ }^{\oplus}$.

Analisando-se os resultados da estimação do modelo, evidenciados na Tabela 2, observam-se seis variáveis contábeis estatisticamente significativas como fatores explicativos do IFDM total, uma vez que os $\beta$ relacionados a tais variáveis (Juros e Encargos da Dívida, Despesa de Capital, Investimentos, gastos com Cultura e Assistência Social, e Transferências Correntes) apresentaram valores-p inferiores ao $\alpha$ estabelecido $(\alpha=0,05)$.

A primeira variável contábil estatisticamente significativa refere-se aos gastos com Juros e Encargos da Dívida, de modo que se observa uma associação negativa entre tais gastos e o IFDM total das entidades analisadas. Dessa forma, o fato de o município destinar montantes ao pagamento de juros, valores estes que poderiam ser investidos em áreas como saúde, educação e emprego, tende a piorar o desenvolvimento humano do município, mensurado, neste estudo, pelo índice FIRJAN de Desenvolvimento Municipal.

A segunda variável contábil considerada significativa como fator explicativo do IFDM total relaciona-se à Despesa de Capital, que, conforme já mencionado, tem por propósito formar e/ou adquirir um bem de capital de modo a contribuir para o incremento da capacidade produtiva. Esperava-se, inicialmente, que fosse verificada uma associação positiva entre os gastos em capital e o IFDM, na medida em que o gasto público com capital aumenta o estoque físico de capital, o que, a princípio, aumentaria a produtividade e promoveria o crescimento (Rocha; Giuberti, 2007). Porém, a relação encontrada foi negativa. Uma possível explicação para a situação supracitada seria o modelo teórico proposto por Devarajan, Swarrop \& Zou (1996), segundo o qual gastos que normalmente são considerados produtivos podem se tornar improdutivos quando são realizados em excesso. Este seria, por exemplo, o caso dos gastos com capital. De acordo com os autores, os países em desenvolvimento alocaram de forma errada os gastos públicos, privilegiando os gastos em capital em detrimento dos gastos correntes, enquanto os países desenvolvidos fizeram o contrário. Consequentemente, os excessivos gastos em capital nos países em desenvolvimento 
os tornaram não produtivos na margem. O estudo de Ghosh e Gregoriou (2008) corrobora esta afirmativa, uma vez que, ao analisar um grupo de 15 países em desenvolvimento, os autores verificaram que a despesa corrente tem impacto positivo no crescimento, enquanto o gasto de capital tem efeito negativo.

A terceira variável contábil significativa foi relacionada aos Investimentos, pressupondo-se que maiores gastos com planejamento e execução de obras, aquisição de imóveis e instalações, equipamentos e material permanente tendem a culminar em uma melhora no desenvolvimento do município.

No que tange aos gastos com Cultura, salienta-se que as despesas concernentes a essa função, conforme afirma Teixeira (2002), fazem parte do grupo das despesas sociais, consistindo em gastos que representam um beneficio direto para a sociedade. De acordo com Rezende (2001), os gastos sociais contribuem para a formação da cidadania e o desenvolvimento comunitário, incentivando e comprometendo na formação das pessoas, propiciando bem-estar e qualidade de vida à sociedade. A variável Cultura apresentou um comportamento positivo como fator explicativo do IFDM total das entidades analisadas, o que era esperado, visto que, quanto maior o gasto com despesas sociais, há tendência de haver uma melhora no desenvolvimento humano.

Em relação à variável Assistência Social, esta também se mostrou significativa como fator explicativo do IFDM total dos entes públicos estudados. No entanto, levando-se em consideração que o objetivo do gasto com Assistência é de caráter distributivo e que as despesas relacionadas a essa função fazem parte do grupo dos gastos sociais, de acordo com a classificação de Rezende (2001) ou das despesas sociais, segundo a classificação de Teixeira (2002), esperava-se uma associação positiva entre esta variável e o IFDM, o que não foi observado. Nesse sentido, a associação negativa encontrada pode indicar um sinal de esgotamento do assistencialismo, de forma que investimentos na qualificação da população, por exemplo, poderiam se mostrar mais eficientes na busca pelo incremento no IFDM.

Finalmente, quanto à variável Transferências Correntes, verificou-se uma associação negativa entre esta e o IFDM. Assim, quanto mais dependentes de transferências da União ou dos estados, menor tende a ser o desenvolvimento do município. Esse resultado é similar ao encontrado pelo Instituto Paranaense de Desenvolvimento Econômico e Social (IPARDES) em estudo realizado em 2003 com base no IDH-M do ano de 2000 no Estado do Paraná. De acordo com a pesquisa supracitada, os municípios com os menores IDH-M apresentavam, também, uma forte relação de dependência das transferências do Governo federal, pautadas substancialmente no Fundo de Participação dos Municípios. No Paraná, dos 288 municípios com IDH-M inferior ao do Brasil, 223 tinham nesse tipo de transferência a principal fonte de receita. Tal dependência indica fraca capacidade de arrecadação dos tributos próprios (IPTU, ISS, taxas e contribuição de melhorias) e de geração do ICMS - tributos que garantem maior autonomia financeira aos municípios (IPARES, 2003).

Caso fosse definido na pesquisa um a de 10\%, a variável Receitas Correntes seria considerada significativa como fator explicativo do IFDM total das capitais analisadas, indicando que a arrecadação de montantes superiores em receitas correntes tenderia a acarretar uma melhora no desenvolvimento humano do município, maximizando o bem-estar da população.

\section{Conclusões}

O impacto dos gastos públicos sobre o desenvolvimento econômico pode ser considerado uma preocupação constante por parte dos governantes. Aliados ao crescimento econômico encontram-se outros aspectos do desenvolvimento humano, tais como saúde e educação. O Índice FIRJAN de Desenvolvimento Municipal (IFDM), de modo similar ao Índice de Desenvolvimento Humano (IDH), procura captar essas três dimensões do desenvolvimento socioeconômico de uma população.

Nesse contexto, o presente estudo teve como objetivo geral identificar as variáveis contábeis condicionantes do IFDM total das capitais brasileiras, de modo a permitir inferências sobre a relevância da informação contábil no índice em questão. Para tanto, a partir do cruzamento dos dados do IFDM total, 
referentes aos exercícios de 2005 a 2010, com os dados das variáveis contábeis das capitais brasileiras disponíveis no site do Tesouro Nacional, realizou-se um estudo de caráter descritivo, utilizando-se análise documental e abordagem quantitativa.

Por meio do modelo de dados em painel com efeitos aleatórios, foi possível estabelecer, entre as variáveis contábeis selecionadas, quais são as realmente condicionantes do IFDM total das 26 capitais brasileiras analisadas. Assim, constatou-se que as variáveis Investimentos e gastos com Cultura apresentaram uma associação positiva e estatisticamente significativa (considerando $\alpha=0,05$ ) com o IFDM total dos entes públicos selecionados, inferindo-se que, quanto maior o gasto com tais funções, maior tende a ser o desenvolvimento humano do município em questão.

As variáveis Juros e Encargos da Dívida, Despesa de Capital e gastos com Assistência Social também se mostraram significativas como fatores explicativos do IFDM dos entes públicos estudados, porém, apresentando sinal negativo. Desse modo, quanto maiores os gastos com tais grupos de contas, menor tende a ser o desenvolvimento do município. Por fim, quanto mais dependentes de Transferências Correntes, menor tende a ser, também, o desenvolvimento do município.

Nota-se, portanto, que as informações contábeis, mais especificamente as variáveis Juros e Encargos da Dívida, Despesa de Capital, Investimentos, gastos com Cultura e Assistência Social, Transferências Correntes (considerando $\alpha=0,05$ ) e Receitas Correntes (considerando $\alpha=0,10$ ), possuem relevância na determinação do IFDM das capitais analisadas, corroborando a afirmativa de cunho teórico segundo a qual os gastos públicos, registrados pela contabilidade, afetam o desenvolvimento de um município. Dessa forma, um bom gerenciamento dessas contas poderia culminar em um aumento no nível de desenvolvimento humano dos municípios estudados ao longo dos anos.

Como limitação da pesquisa, ressalta-se que foi realizado um diagnóstico sobre a situação das capitais brasileiras selecionadas por conveniência, de modo que os resultados não podem ser extrapolados para o restante dos municípios da Federação. Sugere-se, para novos estudos: realizar análises posteriores, com o intuito de verificar se o impacto das variáveis contábeis no IFDM total das capitais brasileiras continua se comportando da mesma forma; verificar o impacto das variáveis contábeis no IFDM, considerando, separadamente, as dimensões Emprego \& Renda, Educação e Saúde; estudar o tema, expandindo o estudo para outras unidades da Federação; e estimar um novo modelo incluindo variáveis de controle não contábeis.

\section{Referências}

Anand, S.; Sen, A. (2000). The Income Component of the Human Development Index. Journal of Human Development, 1(1), pp. 83-106.

Athayde, F. R. (2002). A Evidenciação de informações contábeis da área social no setor público: estudo de caso do município de Luziânia GO. 94 f. Dissertação (Mestrado em Ciências Contábeis) - Programa Multiinstitucional e Inter-Regional de Pós-Graduação em Ciências Contábeis, Universidade de Brasília, Universidade Federal da Paraíba, Universidade Federal de Pernambuco e Universidade Federal do Rio Grande do Norte. Recuperado em: 23 setembro, 201, de http://www.unb.br/cca/ pos-graduacao/mestrado/dissertacoes/mest_dissert_003.pdf.

Baltagi, B. H. (2005). Econometric Analysis of Panel Data. New York: John Wiley \& Sons.

Bressan, V. G. F. (2009). Seguro depósito e moral hazard nas cooperativas de crédito brasileiras. 400 f. Tese (Doutorado em Economia) - Programa de Pós-Graduação em Economia Aplicada, Universidade Federal de Viçosa, Viçosa/MG.

Colauto, R. D.; Nascimento, P. S.; Avelino, B. C.; Bispo, O. N. A. (2009). Evidenciação de Ativos Intangíveis Não Adquiridos nos Relatórios da Administração das Companhias listadas nos Níveis de Governança Corporativa da Bovespa, Revista Contabilidade Vista \& Revista, 20(1), pp. 142-169. 
Corbari, E. C. (2004). Accountability e Controle Social: Desafio à Construção da Cidadania. Cadernos da Escola de Negócios da UniBrasil, 2(1), pp. 99-111.

Cruz, C. F. (2010). Transparência da Gestão Pública Municipal: Referenciais Teóricos e a Situação dos Grandes Municípios Brasileiros. 140 f. Dissertação (Mestrado em Ciências Contábeis) - Programa de Pós-Graduação em Ciências Contábeis, Faculdade de Administração e Ciências Contábeis da Universidade Federal do Rio de Janeiro, Rio de Janeiro.

Devarajan, S.; Swarrop, V.; Zou, H. (1996). The composition of public expenditure and economic growth. Journal of Monetary Economics, 37(2), pp. 313-344.

Ferreira, P. (1996). Investimento em Infra-Estrutura no Brasil. Fatos Estilizados e Relações de Longo Prazo. Pesquisa e Planejamento Econômico, IPEA, 26(2), pp. 234-252.

Ferreira, P.; Malliagros, T. (1998). Impactos Produtivos da Infra-Estrutura no Brasil - 1950/95. Pesquisa e Planejamento Econômico, IPEA, 28(2), pp. 315-338.

FIRJAN. Federação das Indústrias do Estado do Rio de Janeiro: IFDM 2010. Recuperado em 23 setembro, 2011, de http://www.firjan.org.br.

Ghosh, S.; Gregoriou, A. (2008). The Composition of Government Spending and Growth: Is Current or Capital Spending Better? Oxford Economic Papers, 60, pp. 484-516, DOI:10.1093/oep/gpn005.

Gomes, S. C. (2007). Análise Econométrica da Produtividade Total dos Fatores na Amazônia Legal, 19902004. 262 f. Tese (Doutorado em Economia Aplicada), Universidade Federal de Viçosa, Viçosa MG. Recuperado em 22 setembro, 2011 de http://www.economia-aplicada.ufv.br/docs/dissertacoesTeses2007_2009/teses2007/sergio.pdf.

Graciliano, E. A.; Moreira Filho, J. C.; Nunes, A. P.; Pontes, F. C. M.; Zampa, F. F. (2010). Accountability na Administração Pública Federal: Contribuição das Auditorias Operacionais do TCU. Pensar Contábil, 12(47), pp. 43-51.

Gujarati, D. (2006). Econometria Básica. (4 ed.) Rio de Janeiro: Elsevier.

Hood, C. (1991). A Public Management for All Seasons? Public Administration, 69(1), pp. 3-19.

Hsiao, C. (1986). Analysis of panel data. Cambridge: Cambridge University Press.

IPARDES. Instituto Paranaense de Desenvolvimento Econômico e Social. Índice de Desenvolvimento Humano Municipal - IDH-M 2000: anotações sobre o desempenho do Paraná. Recuperado em 18 julho, 2013, de http://www.ipardes.gov.br/biblioteca/docs/idhm_2000.pdf.

Kon, A. (1997). Subsídios teóricos e metodológicos ao planejamento econômico público. EAESP/FGV/NPP - Núcleo de Pesquisas e Publicações. Relatório de pesquisa, 12.

March, J. G.; Olsen, J. P. (1995), Democratic Governance. New York: The Free Press.

Martinez-González, A.; Martí, J. (2006). Accountability and Rendering of Accounts: New Approaches for the Public Sector. International Advances in Economic Research, 12(4), pp. 67-80.

Nakagawa, M.; Relvas, T. R. S.; Dias Filho, J. M. (2007). Accountability: a Razão de ser da Contabilidade. Revista de Educação e Pesquisa em Contabilidade - REPEC, 1(3), pp. 83-100.

NCGA. National Council on Governmental Accounting (1982). Objectives of Accounting and Financial Reporting for Governmental Units, Concepts Statement no. 1. Chicago.

Pablos, N. P.; Figueroa, G. G.; Camou, E. R. (2007). Democratización y rendición de cuentas: el caso de la revisión de las cuentas públicas municipales en Sonora. Gestión y Política Pública, 16(1), pp. 203-236.

Platt Neto, O. A.; Cruz, F.; Ensslin, S. R.; Ensslin, L. (2005). Publicidade e Transparência das Contas Públicas: Obrigatoriedade e Abrangência desses princípios na administração pública brasileira. Anais do Congresso USP de Controladoria e Contabilidade, São Paulo, 5. 
PNUD. Programa das Nações Unidas para o Desenvolvimento: Atlas do Desenvolvimento Humano no Brasil. Recuperado em 23 setembro, $2011 \mathrm{de}$ http://www.pnud.org.br/atlas/tabelas/index.php.

Ray, M. (2012). Accounting for Sustainability - Greening the Human Development Index. Anais do Annual International Conference on Micro and Macro Economics (MME 2012), 2

Rocha, F.; Giuberti, A. C. (2007). Composição do gasto público e crescimento econômico: uma avaliação macroeconômica da qualidade dos gastos dos Estados brasileiros. Economia Aplicada, São Paulo, 11(4), pp. 463-485.

Santana Junior, J. J. B. (2008). Transparência fiscal eletrônica: uma análise dos níveis de transparência apresentados nos sites dos poderes e órgãos dos Estados e do Distrito Federal do Brasil. 176 f. Dissertação (Mestrado em Ciências Contábeis) - Programa Multinstitucional e Inter-regional de Pós-graduação em Ciências Contábeis, Recife.

Santos Filho, M. R. (2010). Desenvolvimento Humano dos Municípios Baianos: uma Avaliação a partir de Indicadores Sociais e das Demonstrações Contábeis. 176 f. Dissertação (Mestrado em Ciências Contábeis) - Universidade Federal da Bahia, Salvador.

Scarpin, J. E. (2006). Estudo dos fatores condicionantes do Índice de Desenvolvimento Humano nos municípios do Estado do Paraná: instrumento de controladoria para a tomada de decisões na gestão governamental. 402 f. Tese (Doutorado em Ciências Contábeis) - Programa de Pós-Graduação em Ciências Contábeis, Faculdade de Economia, Administração e Contabilidade da Universidade de São Paulo, São Paulo.

Slomski, V.; Mello, G. R.; Tavares Filho, F.; Macêdo, F. Q. (2008). Governança Corporativa e Governança na Gestão Pública. São Paulo: Atlas.

Teixeira, M. F. F. (2002). Composição dos Gastos dos Estados Brasileiros, 1983-99. 2002. 88 f. Brasília: ESAF. Monografia premiada em $2^{\circ}$ lugar no VII Prêmio Tesouro Nacional, Tópicos Especiais de Finanças Públicas.

Tesouro Nacional. Finanças do Brasil. Recuperado em 23 julho, 2013 de http://www3.tesouro.fazenda.gov. br/estados_municipios/index.asp.

Tesouro Nacional. Situação Fiscal do seu Município. Recuperado em 23 julho, 2013 de http://www.tesouro.fazenda.gov.br/estados_municipios/situacao_fiscal_municipio.asp.

Wooldridge, J. (2006). Introdução à Econometria: uma abordagem moderna. São Paulo: Pioneira Thomson Learning. 